the reflector is identified with a node, resonance occurs between the gas and the crystal, which manifests itself by a large increase in the current in the maintaining circuit after the manner described by Pierce. Measurement of the wave-length then affords a measure of the composition of the gas mixture.

A demonstration was given of the determination of flame temperatures by spectrum line reversal. An image of the bead of a Pointolite lamp was focussed through a flame on to the slit of a spectroscope. When sodium was introduced into the flame the sodium lines were visible either as bright or dark lines superimposed on a continuous spectrum according as the flame temperature was greater or less than that of the bead. By careful adjustment of the temperature of the latter the sodium lines could be made to disappear. The temperature of the flame was then determined by measuring that of the bead with an optical pyrometer.

In the Optics Division a photo-electric spectrophotometer of general utility was exhibited, and its use for the measurement of ultra-violet absorption was demonstrated. Two monochromators in series are utilised to effect spectroscopic purification of the light from a mercury vapour lamp. The radiation then passes into a photo-electric cell fitted with a quartz window, and the photo-electric current can be measured by either a Lindemann or a Compton electrometer.

In the Electrotechnics Department was to be seen a non-reactive high resistance for use in high voltage alternating current work involving the measurement of very small power factors. Essentially it consists of a number of vertical glass tubes through which tap water can flow, arranged in parallel, and so disposed that two of them which carry the current to be measured are encircled by the remainder. The latter screen the inner tubes, thereby reducing their capacity to earth and the consequent phase error in the current.

The Electrical Standards Division showed new apparatus for building up standard telophonic frequencies. Between the prongs of a tuning-fork controlled by a seconds pendulum is an iron-cored bobbin which is included in the anode circuit of a multivibrator of the same frequency as the fork. By means of a selector circuit loosely coupled to the multivibrator, successive harmonics of the impulse can be picked off.

In the Photometry Division experiments were in progress to determine the effect of a glaring source of light on the ability of the eye to detect bright. ness differences. An observer seated in a totally enclosed cabinet views a field of uniform bright. ness except for a circular central spot the brightness of which can be varied until it is no longer visible to the observer. Under glare conditions a circular spot of very high brightness is included in the field. The least difference of brightness detectable with and without glare can then be determined.

The Wireless Division exhibited an installation for investigating the distribution of current in a vertical cage aerial and for determining whether its variation is sinusoidal under transmitting and receiving conditions. Small ammeters are fixed at convenient intervals inside the aerial in order not to affect the capacity of the latter and are viewed from the ground by means of a telescope.

At intervals during the inspection, demonstrations were given in the William Froude Tank to indicate the manner in which measurements are made of the characteristics and behaviour of model sea-going vessels.

\title{
The Edinburgh Meeting of the Society of Chemical Industry.
}

\begin{abstract}
A DISTINCT biochemical tendency was noticeable $A$ in the cogtributions brought before the annual meeting of Society of Chemical Industry, held at Edinbunon on July 4-9 at the invitation of the Edingurfon and East of Spotland Section of the Soffony. In his interesting presidential address, entitld " Chengfory 1 the Progress of Medicine," Mr. E. H. Car stressed the importance of a close co-operafion betyeen academic laboratories, research institutions, and industrial establishments in the search or new remedial agents, and of an equally effective laison between the chemist, the physiologist, and the physician in elucidating the relation between chemical constitution and therapeutic properties. The body hormones are to be regarded as ideal specific drugs, the detailed study of which should do much to illuminate this problem.
\end{abstract}

Although many such agents are undergoing investigation at the present time, it can be claimed only in two or three instances that the hormone has been isolated as a pure chemical individual. Adrenaline, the active principle of the suprarenal gland which plays an important part in regulating the blood pressure, has been synthesised both in the laboratory and the factory. Recently also, a similar advance has been made by Harington and Barger in the artificial preparation of thyroxine of the thyroid gland; $5 \mathrm{mgm}$. to $10 \mathrm{mgm}$. of this perfectly definite substance may increase the metabolic rate of the human body by so much as 45 per cent. over a period of 14 days. Histamine, another fully characterised substance which has been shown to influence the circulation and respiration, is also apparently produced for functional purposes in the body.
It is possible that such substances are altered and elaborated in various ways in the body before being able to exert the physiological effects which are attributed to them. In general, although the action of a therapeutic agent is probably determined by its chemical constitution, the body mechanism plays an important part in the resultant chemical changes. It appears that the most effective chemotherapeutic agents act through the formation of a depôt from which they are automatically released as required: depôt formation, mechanism of release, and activity in great dilution are indicated as the likely desiderata of chemotherapeutic compounds.

"Most of the bacterial and parasitic diseases, as well as others due to defective functioning, await chemotherapeutic investigation. Chemotherapy is but one of the frontiers of scientific medicine, but it may well prove to be the most important. Certainly this will be so if, in the end, we learn how to stimulate at will the chemical processes of bodily defence, and thus to meet every eventuality, or to prepare substances comparable in activity and specificity with diphtheria antitoxin. Progress lies in the direction of biochemistry and more effective working contact between individuals in chemistry, bacteriology, physiology, and clinical medicine. We need to multiply a hundred times discoveries like those relating to the oxidation and reduction phenomena in the tissues, to the constitution of glutathione and of thyroxine. As these results become known, and with the fuller development of experimental technique, we need bold hypotheses like that of Ehrlich so as to open up new avenues of thought and work."

At a joint meeting with the Biochemical Society

No. 3011, VoL. 120] 
a discussion was held on "The Physiological and Industrial Aspects of the Chemistry of Carbohydrates.' Recent work on structural relationships in the carbohydrate group was reviewed in papers contributed by Prof. W. N. Haworth and Prof. A. R. Ling. Dr. C. G. Lambie, in dealing with the quostion of the intermediary metabolism of carbohydrates, advocated the view that dihydroxyacetone may be a possible common term in the metabolic transformations of carbohydrates, fats, and proteins; an assumed equilibrium of the form glucose $\rightleftharpoons$ dihydroxyacetone, favoured in the forward direction by the presence of insulin, would then explain many of the observed facts of normal and pathological metabolism, including the phenomena of diabetes.

The industrial importance of carbohydrates was emphasised in a paper by Drs. C. J. J. Fox and L. Hall, in which certain recent developments in the cellulose industries were outlined. Despite the present enormous production of artificial silk, it is considered that the further applications of this material are almost unlimited. The rapidly growing demand for wood in industry renders imperative a considered study of forest oconomics and the adoption of a policy of afforestation which will maintain an adequate supply of this indisponsable raw commodity. Of collulose derivatives the acetate is practically non-inflammable and has other advantages over the nitrate, but it has not yet attained the level of quality and price which would enable it to displace the nitrate in the manufacture of filrus, etc. 'The study of the bacterial decomposition of cellulose by methane producers, hydrogen producers, denitriliers, and thermophilic species has recently been renewed with the object of bringing such processes under productive control. A further paper, on "Some Aspects of the Manufacture of Fibrous Celluloses," was read by Dr. J. L. A. Macdonald before the Chemical Engineoring Group of the Society.

A wide field of industrial chemistry was surveyed by the Society's medallist, Col. G. P. Pollitt, in his lecture on "The Development of the Synthetic Nitrogen Industry in (rreat Britain." The decline in the utilisation of fixed nitrogen which immediately followed the War has been followed by a rapid recovery. In 1926 the world's consumption of nitrogen was $1,250,000$ tons, the production having been approximately doubled since 1921. At the present rate of increase of population, and with no alteration in methods of farming, a food shortage is to be anticipated before the end of the present century. As a consequence of the necessity for increasing the output per unit of agricultural land, the nitrogen industry will become one of the most important manufactures, ranking with coal, steel, and shipbuilding. For economic reasons, synthetic nitrogen is gradually replacing Chile saltpetre and by-product ammonia; but such a replacement was rendered possible only through the development in Germany of the Haber-Bosch process. In Great Britain the technique of high-prossure operations has now been mastered, and there is no necessity for this country to continue indefinitely the importation of fixed nitrogen.

Among other important processes which there is a strong promise of doveloping in order to render (Great Britain less dependent on imported raw materials are the production of liquid fuel by the hydrogenation of coal, of synthetic methanol from water-gas, and of acetyleno and acetic acid from coke-oven gas. In the past there has been a tendency for an undue proportion of the most able men in Grent Britain to neglect industry and to enter the services, the law, and other non-productive professions. Provided that in the future our industries have, as in Germany, the first call on the brains of the country, there is every reason to anticipate that Great Britain will continue to lead in the world's industrial development.

Prof. J. Read's lecture on "Natural Sources of Energy in Australia" afforded an appropriate indication of the world-wide interests of the Society of Chemical Industry, which has a strong membership in the Dominions and in the United States. Australia possesses a surprising variety of power resources, located mainly in the eastern coastal zone. The most important of these are black coal, brown coal, and water power; in addition there are relatively unimportant occurrences of natural petroleum (Papua), natural gas (Queensland), and kerosene shale (New South Wales). For the present the vast deposits of brown coal near Melbourne are to be utilised solely by direct combustion of the raw material. Under the auspices of the State Electricity Commission of Victoria the first section of a power-house, with a present capacity of $50,000 \mathrm{kw}$., has been erected at Yallourn; it is proposed eventually to raise the capacity to $150,000 \mathrm{kw}$., and to interconnect the brown-coal power system with the Sugarloaf-Rubicon and Kicwa River hydro-elcetric schemes. The consequent generation of cheap electric power, light, and heat should lead to a steady industrial oxpansion in this area. Hydro-electric power is being rapidly developed, particularly in Tasmania, more than 500,000 h.p. having been located and surveyed in the island. A total amount of 75,000 h.p. is now available from the Great Lake and Shannon River schemes, and factories for the production of electrolytic zinc, carbide, te., have been established in the vicinity of Hobart.

The Universities of Edinburgh, St. Andrews, and Aberdeen, which lie within the area embraced by the local section of the Society, were officially represented at the meeting, and Dr. Kurt Meyer attended on behalf of the German Chemical Society. Prof. A. W. C. Menzies conveyed an invitation from the American Section to hold the annual meeting for 1928 in New York, and this was unanimously accepted.

\section{University and Educational Intelligence.}

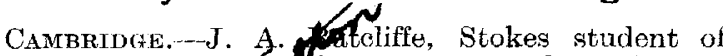
Pembroke Colleg a formerly research student of Sidney Sussex hege, has been olected fellow of

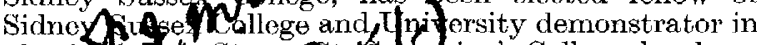
physicf of A. Steer's 'sophane's College, has been appointed Univ frsiby ecturer in geography, and $\mathbf{E}$. G. Dymond, St. J hn's College, University demonstrator in physics.

After some delay, the deeds executed by the late Mr. W. W. Rouse Ball of Trinity College, by which various sums were to be paid to the University, are being completed, and two sums of $£ 25,000$ each will be received for tho foundation of professorships in mathernatics and modern English law, and a further sum of $£ 10,000$, of which the income is to be available for the University Library.

Manchesten.--D. MAM. Maitland has been appointed prafies id bacteriolody and director of the Department of 3 eteriologe fin Preventive Medicine in succession td Prd. (W. W. C. Topley. Prof. Maitland graduated if medicine and surgery in the Tniversity of Toronto in 1916 and obtained the degree of M.D. by thesis in 1922 . He remained at Toronto as lecturer in bacteriology and later as associato

No. 3011 , VoL. 120] 